\title{
Utilization of Rock Mass Parameters for Performance Prediction of Rock TBMs Using Machine Learning Algorithms
}

\author{
Hanan Samadi ${ }^{*}$ and Ebrahim Farrokh ${ }^{2}$
}

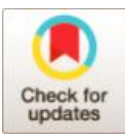

${ }^{1}$ School of Geology, College of Science, University of Tehran, Tehran, Iran

2Department of Mining Engineering, Amirkabir University of Technology, Tehran, Iran.

\section{*Corresponding Author: \\ \e.farrokh@aut.ac.ir}

Received: 15 May, 2021

Accepted: 30 June, 2021

Published: 30 July, 2021

\begin{abstract}
Existing rock mass parameters, such as uniaxial compressive strength (UCS), rock quality designation (RQD), and distance between planes of weakness (DPW), are being widely used in the prediction of TBM performance in various hard rock conditions. In this paper, these factors are considered as input parameters to estimate the rate of penetration (ROP) based on 180 compiled data from two projects including the Queens water tunnel lot 3, Stage 2 in USA and KarajTehran water transfer tunnel in Iran. This study aims to evaluate the influence of rock mass parameters on TBM performance and develop a new empirical equation to estimate ROP using multivariate regression analysis and artificial intelligence algorithms. In this regard, by taking advantage of machine learning algorithms, two types of artificial intelligence techniques, including particle swarm optimization (PSO) and radial basis function network (RBF), have been employed to develop predictor networks to estimate TBM performance. To explain the relationships among rock mass parameters and ROP and to offer new empirical equations, regression analysis is also utilized. The proposed models have been validated based on the various machine learning loss functions including, MAD, RRSE, rRMSE, MSE, MAPE, and sensitivity analysis. The obtained results demonstrate that the calculated values are in good agreement with the actual data.
\end{abstract}

Keywords: TBM performance, Penetration rate, Machine learning, Rock mass properties

between planes of weakness (DPW) to provide a prediction model for similar conditions. The machine specifications such as cutterhead and disc cutter diameter are fixed during tunnel construction. So, they cannot be used as an input in the soft computing techniques for developing new empirical models.

The predictor networks have developed to estimate the TBM performance in hard rock conditions, including the penetration rate and advance rate, using the soft computing method and artificial intelligence techniques, which are well-known due to their accuracy and efficiency, their strong predictive authority, and using numerous range of parameters in the determined network's database [1-6].

For instance, Benardo and Kaliampakos (2004) employed an artificial neural network (ANN) to estimate TBM advance rate in hard rock conditions parameters including, uniaxial compressive strength (UCS), rock quality designation (RQD), and distance 
using rock specifications, including RQD, weathering degree, RMR, permeability, and hydrological condition [7]. In another example, the advance rate and penetration rate of TBM tunneling were investigated by Yagiz and Karahan (2015) using PSO soft computing technique. In this prediction, the input parameters divided into three categories, including operating parameters (thrust force, cutterhead rotation speed), rock mass properties (core fracture frequency (CFF), and uniaxial compressive strength (UCS)) and disc cutter's diameter as of the major machine specifications [8]. Gao and Li (2015) have executed the partial least squares (PLS) and support vector machine (SVM) methods to predict penetration rate considering five-rock mass parameters including, UCS, peak slope index (PSI), Brazilian tensile strength (BTS), the distance between the planes of weakness (DPW) and angle between the plane of weakness $(\alpha)$ [9]. Shao et al. (2013) employed an extreme learning machine (ELMAI) to calculate the penetration rate based on the rock mass properties, including $\alpha, \mathrm{DPW}, \mathrm{UCS}$, and PSI [10]. Jinhuili et al. (2021) have applied a long-short term memory recurrent neural networks (LSTM-RNN) technique to measure the operational parameters, including torque and thrust of the TBM in a real-time manner with consideration of rock mass classification and rock mass grade [11]. Samadi et al. (2021) employed an artificial neural network (ANN) and support vector machine (SVM) to estimate maximum surface settlement caused by EPB machine in urban areas based on the collected 50 data [12]. Samadi and Hassanpour (2020), have performed the GRU-RNN network for estimation of the chamber pressure based on 4180 collected data [13]. Farrokh et al. (2012) investigated several models to estimate TBM penetration rate [14]. Farrokh (2012) collected and compiled information for 300 tunnel projects, including rock properties, TBM specifications, TBM operational parameters, and achieved performance to look for considerable correlations between these parameters [15].

This study aims to employ two predictor models including, particle swarm optimization (PSO) and radial basis function network (RBF), and multivariable regression analyses for developing empirical models to predict the TBM penetration rate based on a database developed by collecting required data from the Queens water tunnel lot 3, Stage 2 in the USA and Karaj-Tehran water transfer tunnel in Iran. These tunnels have been constructed using hard rock TBMs. The obtained results of models were evaluated using the superior loss functions of machine learning.

\section{Project Description}

To verify the predictability of the PSO and RBF-based ROP prediction model proposed herein, these models were applied in two tunneling projects excavated by hard rock TBMs. The main characteristics of these two TBM tunneling projects are summarized in Table 1.

The Queens water tunnel passes through five rock types, including gneiss, orthogneiss, amphibolite, granitic gneiss, and rhyodacite dyke. The gneiss unit is the most dominant rock type encountered along the tunnel alignment, with a $41 \%$ percentage. Also, the rhyodacite dyke has less percentage encountered along the tunnel $(2.5 \%)$ (Figure 1, a). The location of stage two of Queens tunnel no. 3, New York City, is indicated in Figure 1, b [16]. This tunnel has a diameter of $7.06 \mathrm{~m}$ and a length of $7.5 \mathrm{Km}$. The torque and thrust values of the cutterhead at a maximum rotation speed of 8.3 RPM are 3620 kN.m and $15592 \mathrm{KN}$, respectively. The TBM cutterhead is equipped with 50 disc cutters in the central and peripheral parts [17].

Table 1

Characteristics of tunneling projects

\begin{tabular}{|c|c|c|c|c|c|c|}
\hline No. & Project & $\begin{array}{c}\text { Tunnel } \\
\text { length }(\mathrm{km})\end{array}$ & $\begin{array}{l}\text { TBM } \\
\text { type }\end{array}$ & $\begin{array}{l}\text { TBM type and } \\
\text { manufacturer }\end{array}$ & $\begin{array}{c}\text { TBM } \\
\text { diameter }(\mathrm{m}) \\
\end{array}$ & $\begin{array}{c}\text { Overburden } \\
\text { (m) }\end{array}$ \\
\hline 1 & $\begin{array}{l}\text { Queens water tunnel } \\
\text { lot 3, Stage } \\
2 \text { (USA) }\end{array}$ & 7.5 & & $\begin{array}{c}\text { TBM 235-282 } \\
\text { (Robbins) }\end{array}$ & 7.06 & 200 \\
\hline 2 & $\begin{array}{l}\text { Karaj-Tehran water } \\
\text { transfer tunnel (Iran) }\end{array}$ & 30 & $\begin{array}{l}\text { Double } \\
\text { shield }\end{array}$ & $\begin{array}{c}\text { TBM-S323 } \\
\text { (HERRENKNECHT) }\end{array}$ & 4.65 & \\
\hline
\end{tabular}

In Karaj-Tehran water transfer tunnel project, the data sets related to geomechanical conditions and machine specifications were collected during the preconstruction and construction phases. This line is located in the northwest of Tehran, which connects the KWC dam to Tehran, through a $30 \mathrm{~km}$ tunnel with a diameter of $4.65 \mathrm{~m}$, with 12 stations. The excavation process has been accomplished using a TBM-S323 manufactured by HERRENKNECHT. The torque and thrust values of the cutterhead at a maximum rotation speed of 11 RPM are 1029 kN.m and $169.3 \mathrm{KN}$, respectively. The TBM cutterhead is equipped with 31 disc cutters in the central and peripheral parts.

The collected dataset was derived in the range of 1500 segmental rings with a width and thickness of 1.5 meters. This tunnel is located mainly through four 
rock types, including siltstone and sandstone, siliceous tuff and green vitric, lithic tuff, and micro

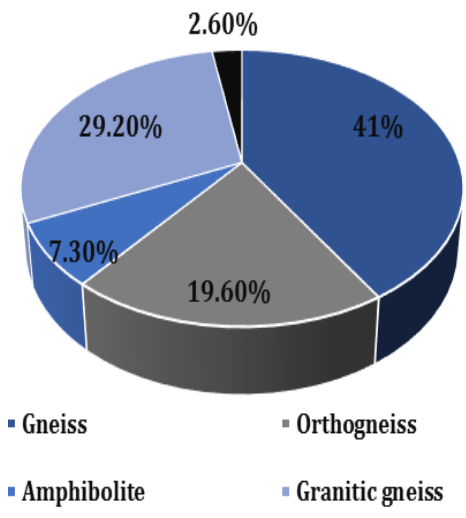

- Rhyodocite dike conglomerate. A geographical situation of the project is presented in Figure 2.

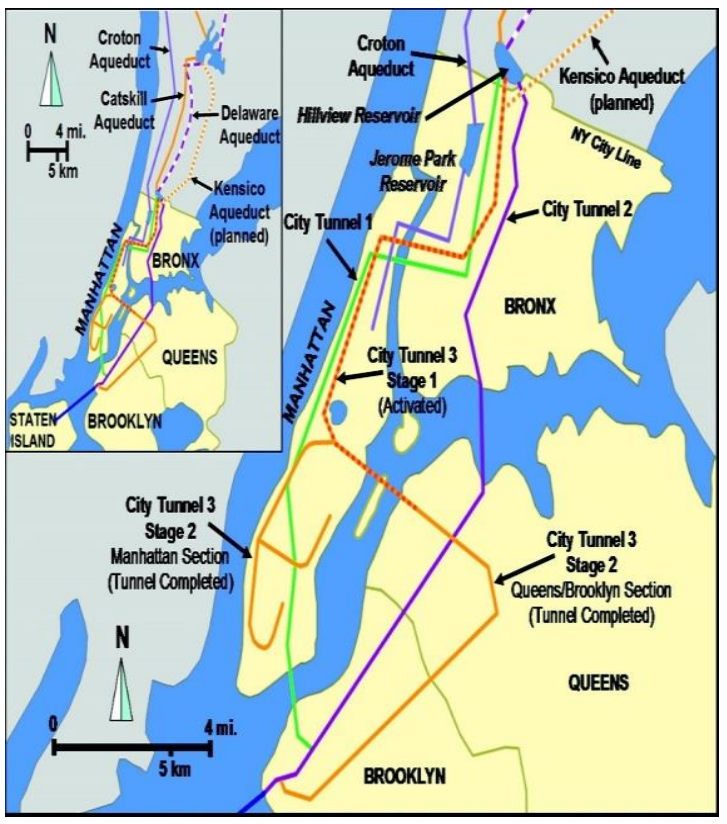

(b)

Figure 1. (a): Percentage of various rock units encountered along the tunnel alignment, (b): Location of stage two of Queens tunnel no. 3, project area in New York City (b: [16])

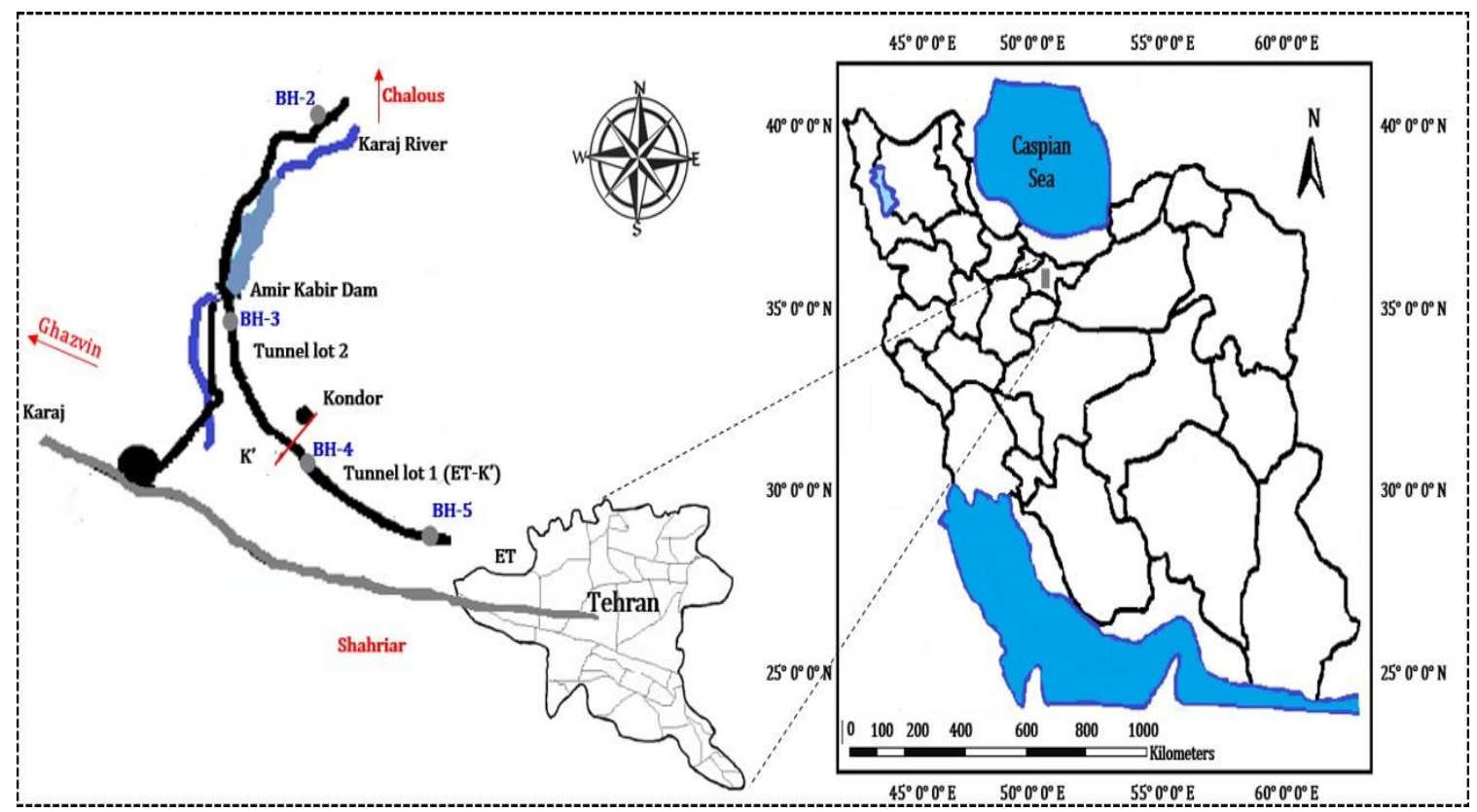

Figure 2. Location of Karaj-Tehran water transfer tunnel, Iran 


\section{Database Development}

The geomechanical properties of the projects noted above were studied in both field and laboratory to establish the database required to develop predictive performance models. Three rock mass parameters are identified as influential parameters for the TBM penetration rate including RQD, UCS, and DPW. In general, all of these three independent parameters play critical roles in the variation range of TBM performance. Statistical characteristics of the

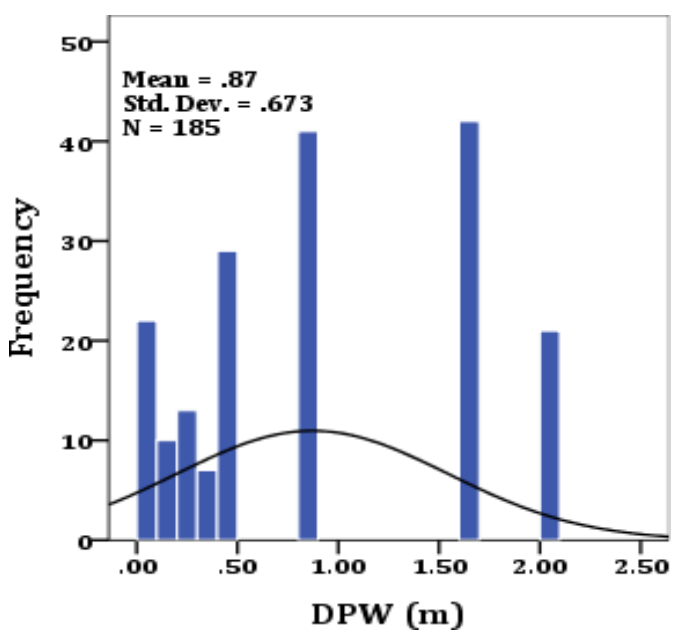

(a)

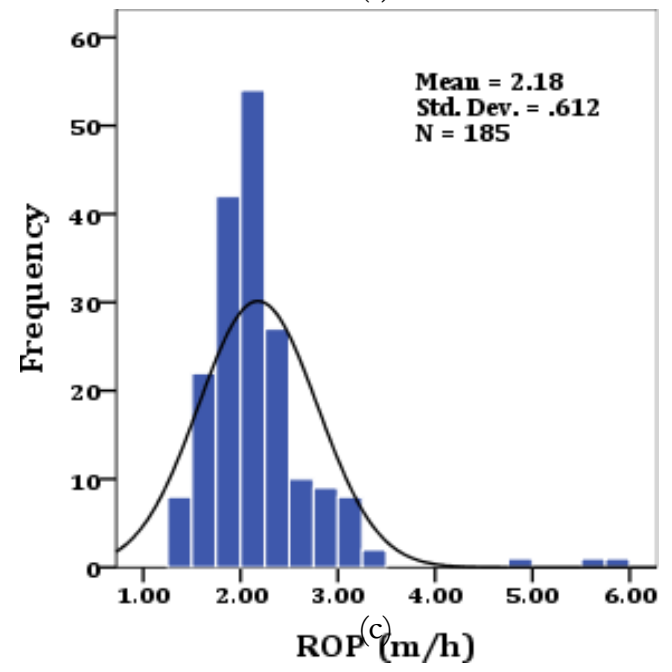

parameters recorded in the database are summarized in Table 2. Also, the histograms and distribution curves of rock characteristics and TBM penetration rate recorded in the database are indicated in Figure 3.

In this study, the collected data was divided into two categories. 85\% (153 samples) were randomly selected for training the network, and the remaining dataset $(28$ samples) were considered the test data to evaluate the training process.

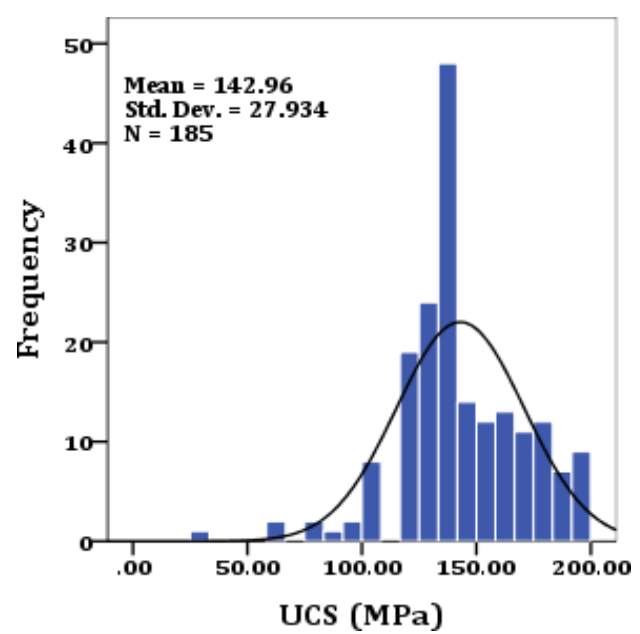

(b)

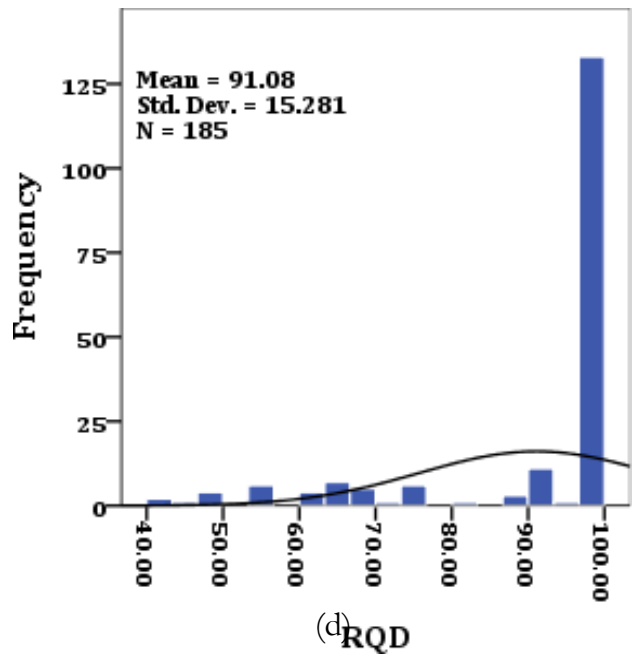

Figure 3. Distribution curve and frequency histogram of rock mass parameters and penetration rate in the database

Table 2

Summary results of descriptive statistical analysis of parameters recorded in the database

\begin{tabular}{llllllllll}
\hline Parameter & Categ. & Min. & Max. & Ave. & St.D & Var. & Skew. & Kurt. & Med. \\
ROP & Output & 1.27 & 5.8 & 2.18 & 0.61 & 0.37 & 2.76 & 13.8 & 2.08 \\
RQD & Input & 40.6 & 99.8 & 91.07 & 15.28 & 233.5 & -1.75 & 1.8 & 99.28 \\
DPW & Input & 0.05 & 2 & 0.87 & 0.67 & 0.45 & 0.41 & -1.33 & 0.8 \\
UCS (MPa) & Input & 30 & 199.7 & 142.9 & 27.9 & 780.3 & -0.4 & 1.38 & 139.3 \\
\hline
\end{tabular}




\section{Results and Discussion}

Predicting ROP is a non-linear and multivariable complex problem that depends on many parameters. The ROP may rely on various rock mass properties, including RQD, UCS, DPW, $\alpha$, and TBM specifications such as cutterhead and disc cutter's diameter. So, the problem is highly complicated to be solved with a simple linear regression approach. It is commonly accepted that rock properties have a significant effect on TBM performance. Thus, artificial intelligence techniques such as PSO and RBF are used to estimate the TBM performance as a non-linear function of hard rock properties.

In this study, to develop the precise models, the collected dataset was divided into two types along the tunnel from the two projects in accordance with geomechanical engineering units. Afterwards, the models are developed using various computational algorithms, including PSO and RBF. Then the multivariable regression (MVR) was also applied to obtain an empirical equation to estimate TBM penetration rate.

\section{Developing new empirical equations}

In the present study, to find an empirical equation to relate TBM penetration rate as a function of geomechanical conditions, the multivariate regression (MVR) method was used. Empirical equations have great importance during tunneling, which is obtained based on actual data along the tunnel. For this purpose, some geomechanical parameters of hard rock materials (RQD, UCS, and DPW) were used as independent variables, and the recorded penetration rate was treated as a dependent variable. Figure 4 provides the correlations and the relevant equations for the penetration rate considering various rock mass parameters.

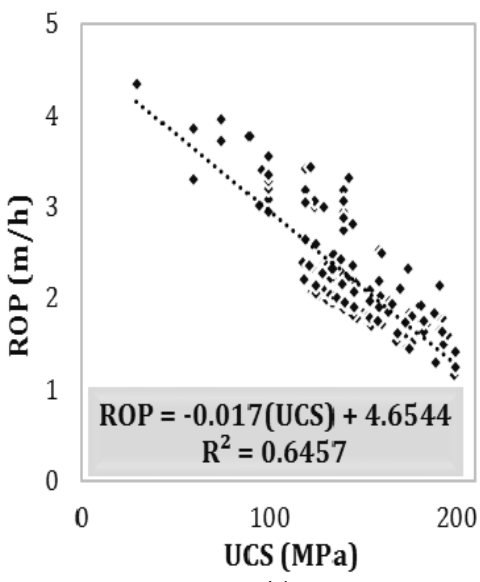

(a)

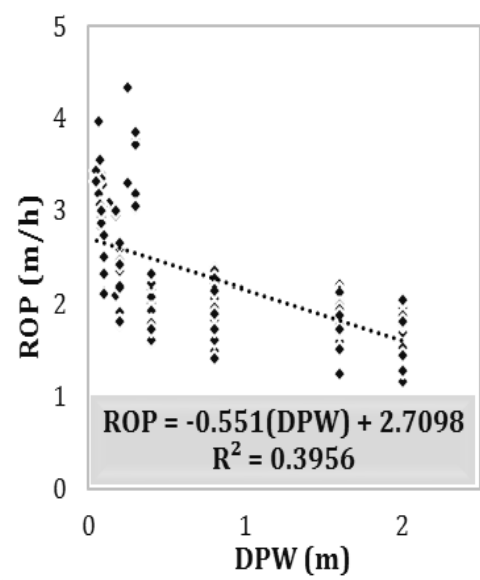

(b)

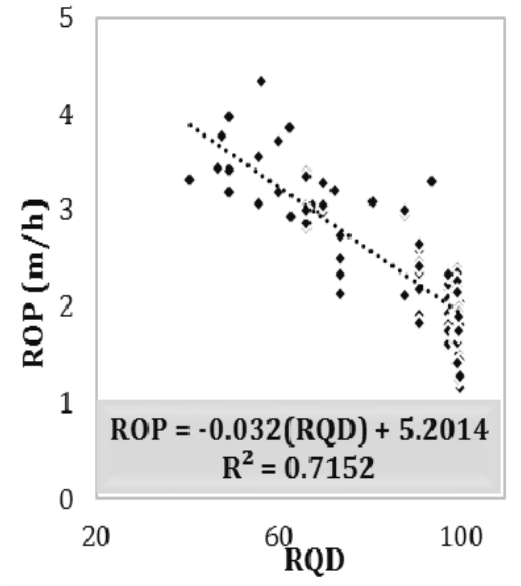

(c)

Figure 4. The correlation between penetration rate and rock mass parameters

Eq. 1 shows the regression formula obtained from SPSS software to evaluate the influence of each input variables on ROP:

$\mathrm{ROP}(\mathrm{m} / \mathrm{h})=5.765-0.012 \mathrm{UCS}-0.018 \mathrm{RQD}-0.207$ DPW (1)

Where RQD is rock quality designation, UCS (Mpa) and DPW (m) refer to the uniaxial compressive strength, and distance between planes of weakness, respectively. The comparison of predicted data with the newly developed equation and the measured penetration rate is indicated in Figure 5. As seen, measured data are in good agreement with the actual data. Also, the statistical histograms for measured and calculated results are presented in Figure 6. As seen, measured data show the same trend as the general trend of the actual data. The obtained results were evaluated based on the loss functions such as MAD, RRSE, rRMSE, RMSE, MSE, and MAPE (Table 3), which indicate the best correlation between the actual and predicted results.

Table 3

Results of the loss functions for the evaluation of MVR

\begin{tabular}{lcccccc}
\hline Func. & MAD & MSE & RMSE & rRMSR & MAPE & RRSE \\
\hline MVR & 0.003297 & 0.000325 & 0.018035 & 0.005308 & 0.083895 & 9.9494 \\
\hline
\end{tabular}




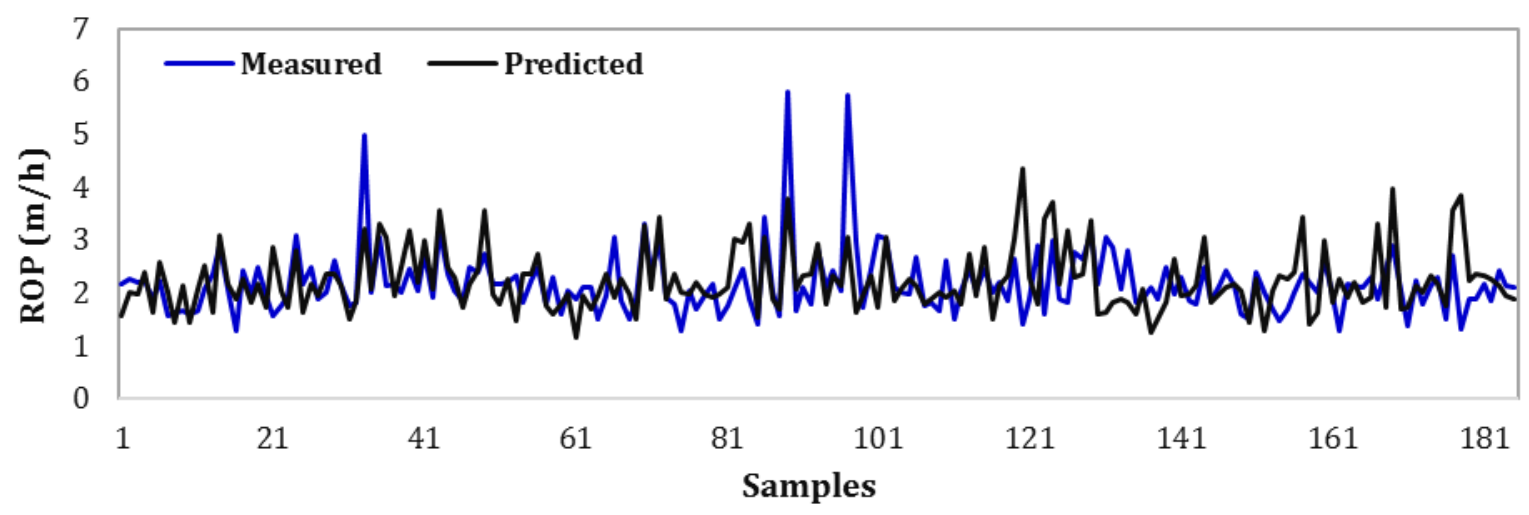

Figure 5. The comparison between the measured and predicted results based on MVR method

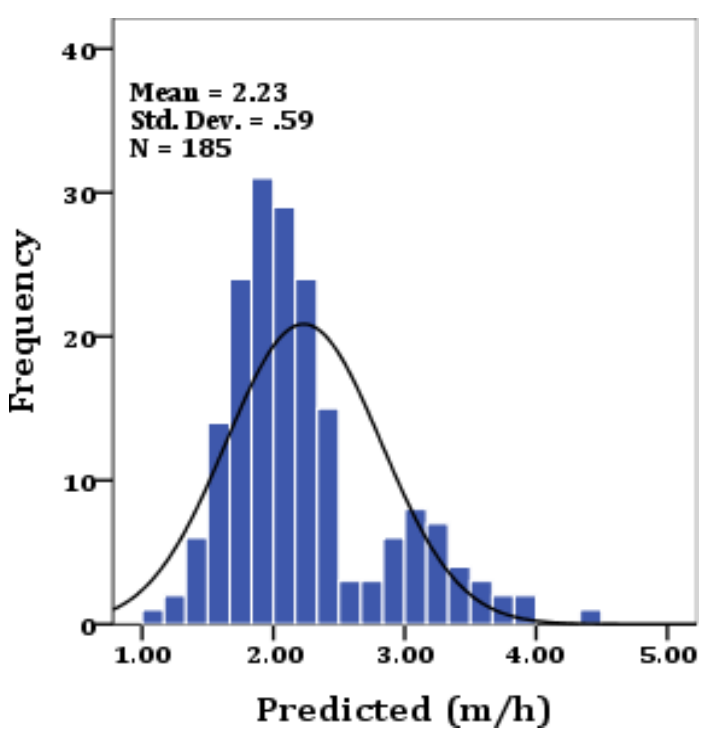

(a)

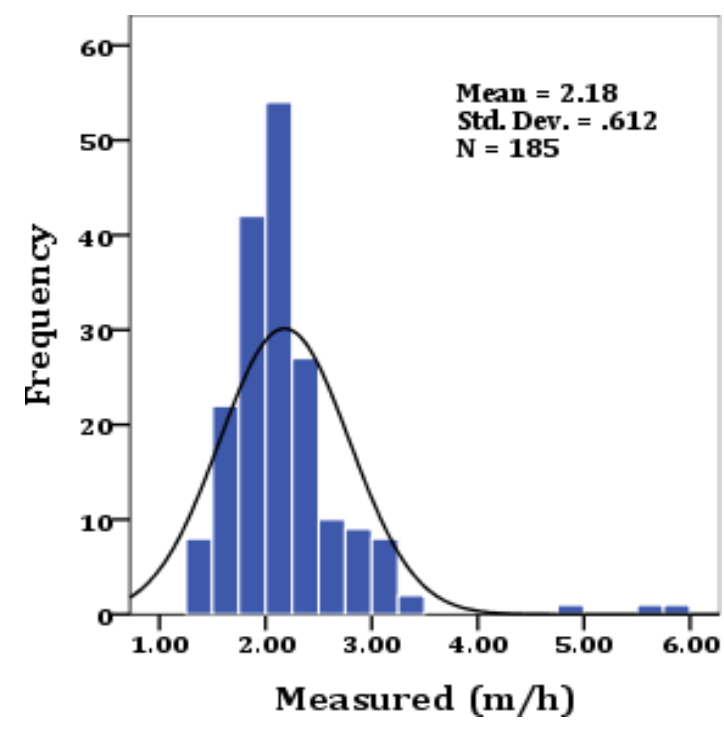

(b)

Figure 6. Distribution curves and frequency histograms of measured and predicted TBM penetration rate

Sensitivity analysis is a method to determine whether the input uncertainty can affect uncertainty in its target variables related to the independent input variables. This analysis has a significant focus on uncertainty quantification and it determines the robustness of an assessment. The practical way to indicate the results of sensitivity analysis is a tornado diagram that shows the effect of each input parameter on the output variable when the input parameter is varied.

In this study, the process of recalculating outputs under alternative assumptions to determine the impact of geological parameters along the tunnel under sensitivity analysis could be helpful to indicate the variables which have the highest effect on the TBM penetration rate. Changes in ROP values in terms of percentage are presented in Figure 7 when the input parameters are varied. In this diagram, the results show that the DPW has the least effect on ROP, however, UCS and RQD have higher influence on ROP prediction.

\section{Particle swarm optimization (PSO) technique}

The PSO technique was developed by Kennedy and Eberhart (1995) as an optimization algorithm based on artificial intelligence. This algorithm is inspired by swarm behavior such as bird flocking and schooling in nature. PSO has been widely used, and it is the inspiration for a new research area called swarm intelligence. The crossover and mutation are not determined as evolution operators in this method. However, PSO has potential solutions, namely, particles that move in the problem space. This movement was occurred by following the current optimum particles. There are two vital influential factors in PSO for calculations, including the speed and memory requirements [18]. The structure of the PSO algorithm is presented in Figure 8 (a). The velocity and particle's position at each generation were updated based on the inertia weight, accelerations, and two independent

random numbers. 


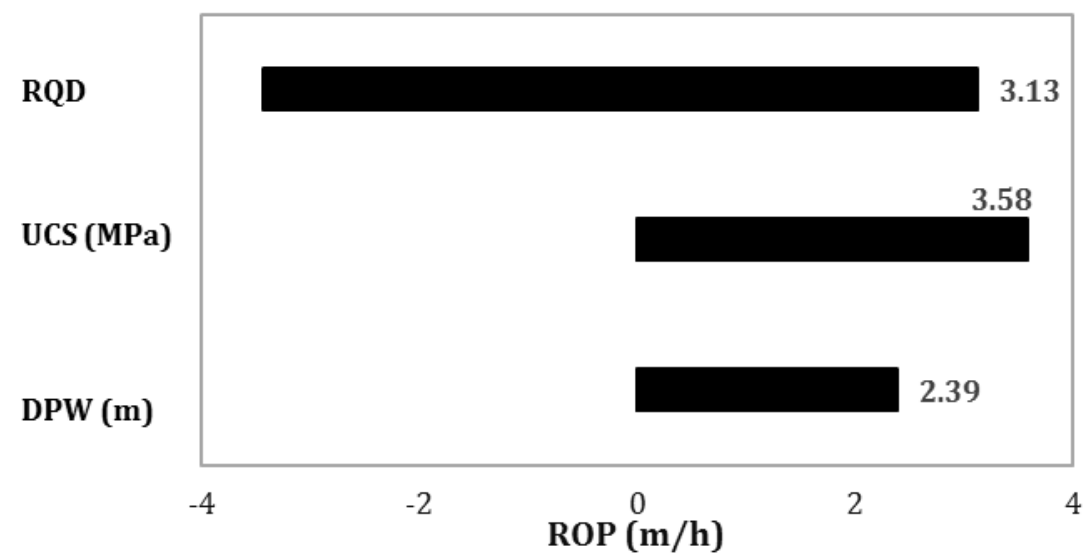

Figure 7. Sensitivity analysis using Tornado grap for MVR model

\section{Radial basis function (RBF)}

The values of the RBF method depend on the distance between the inputs and fixed points. This function assigns an actual value to each input and the value predicted by the network cannot be negative. Broomhead and lowe (1988) indicated that RBF has traditionally been associated with radial functions in a single-layer network [19]. The structure of this model is shown in Figure 8 (b). Three-layer were determined in the training stage including, input layers, hidden layers, and output layers. For increasing the linear separability of the feature vector, the dimension of the feature vector must be increased.

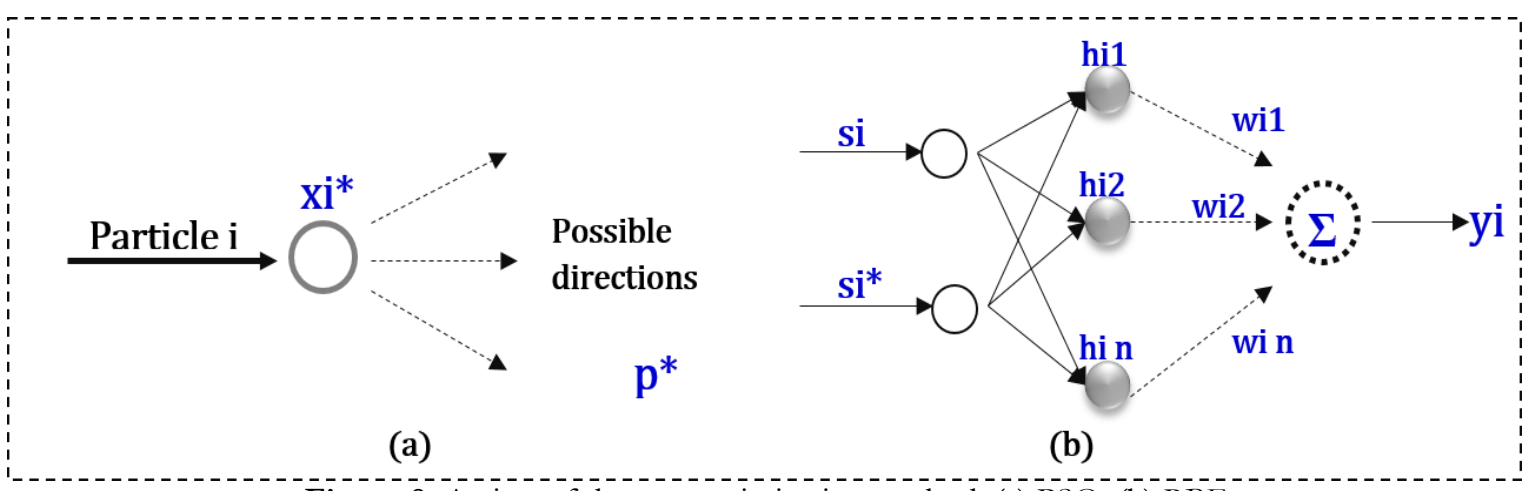

Figure 8. A view of the two optimization method, (a) PSO, (b) RBP

Results of artificial intelligence methods

In these techniques, several tests run to develop the network architecture that produces more consistent results. Figure 9 shows graphs comparing the measured and predicted data for the preferred models. In these models, reliable results are obtained. Artificial intelligence's performance is assessed in terms of the value's loss functions in training and testing stages, between the actual and the predicted penetration rate. The obtained results of loss functions are indicated in Table 4. These results show a close relationship between the measured and predicted values. Comparison of predicted target values using proposed models and output values measured for 27 datasets from the testing phase is shown in Figure 10.

Table 4

Results of loss functions for evaluation of the neural networks

\begin{tabular}{llcccccc}
\hline Func. & & MAD & MSE & RMSE & MAPE & RRSE & rRMSE \\
\hline RBF & Train & 0.0015 & $2.4 \mathrm{E}-06$ & 0.0015 & 0.069 & 0.94 & 0.0017 \\
& Test & 0.011 & 0.03 & 0.17 & 0.21 & 1.49 & 0.001 \\
PSO & Train & 0.001 & $3.9 \mathrm{E}-05$ & 0.0062 & 0.037 & 0.76 & 0.003 \\
& Test & 0.00041 & $8.1 \mathrm{E}-05$ & 0.009 & 0.288 & 0.505 & 0.079 \\
\hline
\end{tabular}




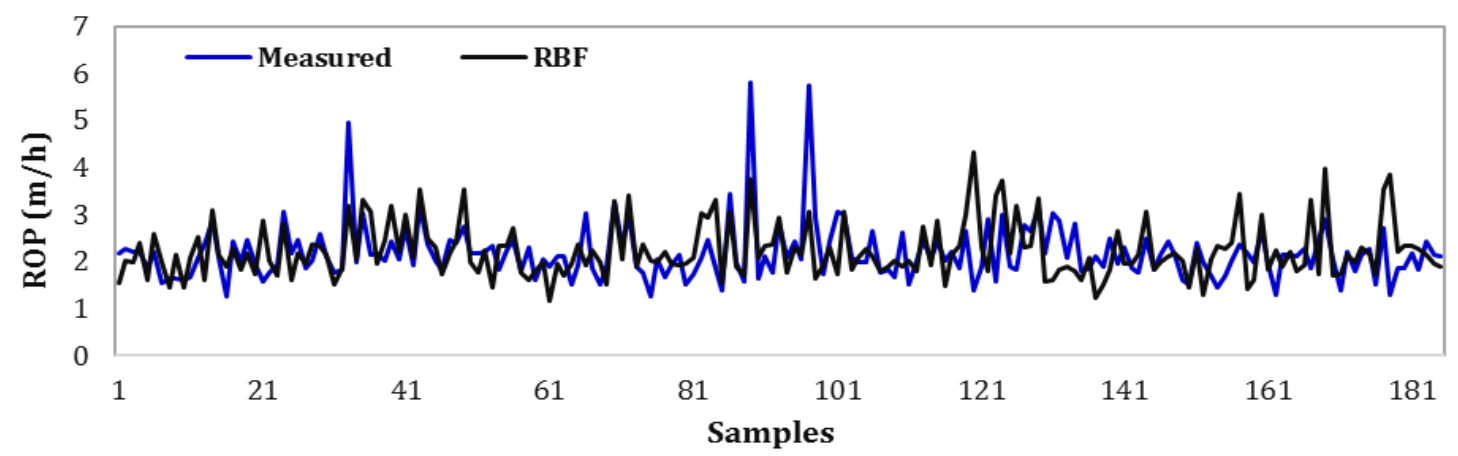

(a)

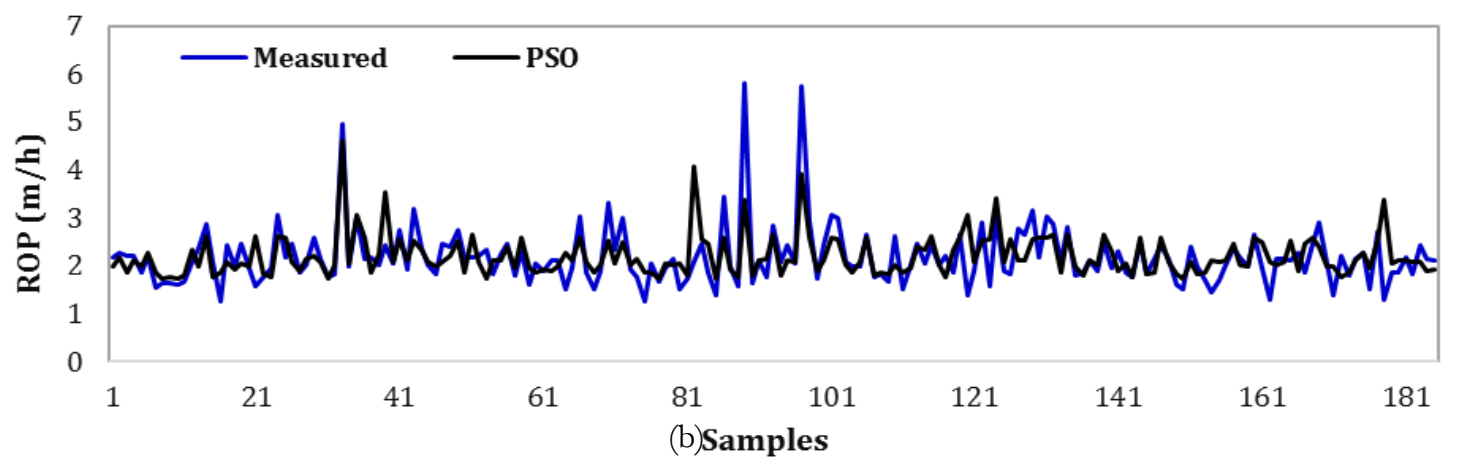

Figure 9. Results of models; Comparison of measured and predicted values of ROP (a) RBF, (b) PSO

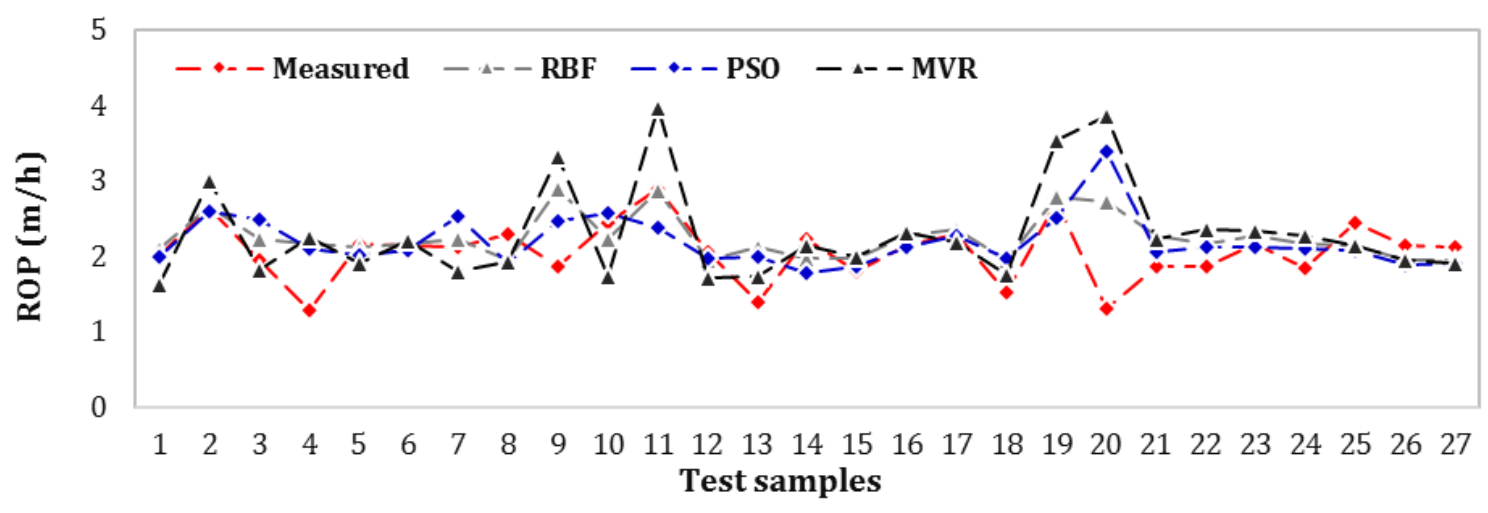

Figure 10. Comparison of measured and predicted values by different models for 27 testing datasets

\section{Conclusion}

The development of artificial intelligence methods for modeling TBM penetration rate (ROP) has been well accepted through the scientific community, as the various attempts made in geotechnical projects such as mechanized tunneling proved their efficiency.

In this study, different models were developed using PSO, RBF, and MVR techniques. As a result, to develop the generalized models for the prediction, these methods were developed using a randomly selected training dataset (comprised of $85 \%$ of the whole dataset) and a testing dataset (comprised of 15\% of the whole dataset).

The statistical indices such as MAD, RRSE, rRMSE, RMSE, MSE, and MAPE were calculated to evaluate the deviation between the model outputs and the measured values. As a result, the performance of machine learning techniques is seen to be significantly better than all other models. The most reliable and encouraging results were obtained with these methods and are superior to others. 
To obtain an empirical equation, MVR analysis is also conducted. The results show that the developed model References

1. Alvarez Grima M, Bruines PA, Verhoef PNW. Modeling tunnel boring machine performance by neuro-fuzzy methods. Tunnell Underground Space Technol. 2000; 15(3).

2. Ge Y, Wang J, Li K. Prediction of hard rock TBM penetration rate using least square support vector machine. 13th IFAC Symposium on Large Scale Complex Systems: Theory and Applications, China, 2013; 7-10.

3. Tao H, Jingcheng W, Langwen Z. Prediction of hard rock TBM penetration rate using random forests. Proceedings of the $27^{\text {th }}$ Chinese Control and Decision Conference, IEEE, China, 2015; 3716-3720.

4. Yagiz S, Gokceoglu C, Sezer E, Iplikci S. Application of two non-linear prediction tools to the estimation of tunnel boring machine performance. Appl Eng Artifici Intel. 2009; 22: 808-814.

5. Yagiz S, Karahan H. Prediction of hard rock TBM performance rate using particle swarm optimization. Int J Rock Mechan Min Sci. 2011; 48: 427-433.

6. Yoo C, Kim J. Tunneling performance prediction using an integrated GIS and neural network. Comput Geotech J. 2007; 34: 19-30.

7. Benardos A, Kaliampakos D. Modelling TBM performance with artificial neural networks. Tunnel Underground Space Technol. 2004; 19: 597-605.

8. Yagiz S, Karahan H. Application of various optimization techniques and comparison of their performances for predicting TBM penetration rate in rock mass. Int J Rock Mechan Min Sci. 2015; 8: 308-315.

9. Gao L, Li X. Utilizing partial least square and support vector machine for TBM penetration rate prediction in hard rock conditions. J Centr $S$ Univ. 2015; 22: 290-295.

10. Shao C, Li X, Su H. Performance prediction of has good accuracy, hence can be readily used to estimate the rate of penetration. hard rock TBM based on extreme learning machine. In: Lee J, Lee MC, Liu H, Ryu JH. editors. ICIRA: Intelligent robotics and applications. Lecture notes in computer science, Berlin-Heidelberg: Springer, 2013; 8103: 409e16. 11. Li J, Li P, Guo D, Li X, Chen Z. Advanced prediction of tunnel boring machine performance based on big data. Geosci Front. 2021; 12(1): 331-338.

12. Samadi H, Hassanpour J, Farrokh E. Maximum surface settlement prediction in EPB TBM tunneling using soft computing techniques. ICCEET Conf. 2021.

13. Samadi H, Hassanpour J. Analysis the stability of work face in EPB tunneling using deep learning (GRU) and PCA techniques. $\sigma^{\text {th }}$ Dam Tunnel Conf Exhib. 2021.

14. Farrokh E, Rostami J, Laughton C. Study of various models for estimation of penetration rate of hard rock TBMs. Tunnel Underground Space Technol. 2010; 30: 110123.

15. Farrokh E. Study of utilization factor and advance rate of hard rock TBMs. PhD. Thesis, Pennstate University, USA. 2012.

16. Baskerville CA, Mose GD. The separation of the Hartland formation and Ravenswood granodiorite from the Fordham gneiss at Cameron's line in the New York City area, Northeastern Geol. 1989; 11(1): 22-28.

17. Khalighi BB, Diehl JJ. High performance tunnel boring machine for Queens Water Tunnel No. 3: A design and case history. In: Proceeding of the rapid excavation and tunneling conference (RETC), Chapter 11, SME publication. 1997.

18. Kennedy J, Eberhart R. Particle swarm optimization. Proceedings of ICNN'95 - International Conference on Neural Networks. 1995.

19. Broomhead D, Lowe D. Radial basis functions, multi-variable functional interpolation and adaptive networks. Royal Signals and Radar Establishment Malvern, United Kingdom. 1988.

\section{SJFST}

Copyright: (C) 2021 The Author(s); This is an open-access article distributed under the terms of the Creative Commons Attribution License (http://creativecommons.org/licenses/by/4.0), which permits unrestricted use, distribution, and reproduction in any medium, provided the original work is properly cited.

Citation: Samadi H, Farrokh E. Utilization of Rock Mass Parameters for Performance Prediction of Rock TBMs Using Machine Learning Algorithmsin. SJFST, 2021; 3(3):1-9.

https://doi.org/10.47176/sjfst.3.3.1 